\title{
Interleukin (IL)-21 promotes intestinal lgA response to microbiota
}

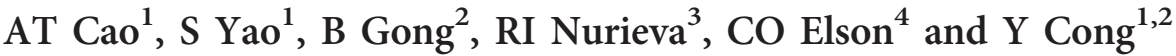

Commensal microbiota-specific T helper type 17 (Th17) cells are enriched in the intestines, which can convert into T follicular helper (Tfh) in Peyer's patches, and are crucial for production of intestinal immunoglobulin A (IgA) against microbiota; however, the role of Th17 and Tfh cytokines in regulating the mucosal IgA response to enteric microbiota is still not completely known. In this study, we found that intestinal IgA was impaired in mice deficient in interleukin (IL)-17 or IL-21 signaling. IL-21, but not IL-17, is able to augment B-cell differentiation to IgA ${ }^{+}$cells as mediated by transforming growth factor $\beta 1$ (TGF $\beta 1$ ) and accelerate IgA class switch recombination (CSR). IL-21 and retinoic acid (RA) induce IgA ${ }^{+}$ B-cell development and IgA production and drives autocrine TGF $\beta 1$ production to initiate IgA CSR. Repletion of T-celldeficient TCR $\beta \times \delta^{-\prime-}$ mice with Th17 cells specific for commensal bacterial antigen increased the levels of IgA ${ }^{+} B$ cells and IgA production in the intestine, which was blocked by neutralizing IL-21. Thus IL-21 functions to strongly augment IgA production under intestinal environment. Furthermore, IL-21 promotes intestinal B-cell homing through $\alpha_{4} \boldsymbol{\beta}_{7}$ expression, alone or with TGF $\beta$ and RA. Together, IL-21 from microbiota-specific Th17 and/or Tfh cells contributes to robust intestinal IgA levels by enhancing $\lg \mathrm{A}^{+} \mathrm{CSR}$, IgA production and B-cell trafficking into the intestine.

\section{INTRODUCTION}

The human intestinal tract is home to $>100$ trillion microorganisms, the majority of which reside peacefully without insult or challenge to the host. The mucosal surfaces are the most frequent access point for the microbiota, which is lined by a single layer of epithelial cells. Breach of the epithelial layer by pathogens results in enteric infections and disease, while chronic infiltration by the commensal microbiota leads to continued exposure and activation of the intestinal immune system. ${ }^{1}$ Over time, chronic and dysregulated immune responses against the commensal microbiota results in increased inflammation and the onset of inflammatory bowel disease. ${ }^{2}$ Among the multiple regulatory mechanisms regulating host response to microbiota, immunoglobulin A ( IgA), which is enriched in mucosal secretions, has crucial roles in the maintenance of intestinal homeostasis against microbiota. IgA functions to neutralize and aid in clearance of extracellular pathogens by preventing adherence to epithelial surfaces and limiting access to the intestines and the immune system. ${ }^{3}$ The high level of IgA production is driven by microbial colonization of the intestine, as germ-free mice have low levels of IgA and $\mathrm{IgA}^{+} \mathrm{B}$ cells, whereas colonization with commensal bacteria restores IgA production, ${ }^{4}$ and the majority of intestinal plasmablasts produce antibodies that are specific for intestinal antigens. ${ }^{5}$ Notably, monocolonization of germ-free mice with segmented filamentous bacteria (SFB) selectively increases IgA production and secretion, ${ }^{6}$ and intestinal IgA deficiency in mice leads to SFB overgrowth. ${ }^{7}$ A recent report revealed that colonization by SFB induced both $\operatorname{IgA}^{+} \mathrm{B}$ cells and $\mathrm{T}$ helper type 17 (Th17) cells in multiple locations in the intestine. ${ }^{8} \mathrm{With}$ the observations that SFB colonization can control both Th17 cells and IgA production, it therein suggests a link between intestinal $\mathrm{T}$-cell function and IgA production.

As with all subtypes of CD4 ${ }^{+} \mathrm{T}$ cells, Th17 and $\mathrm{T}$ follicular helper (Tfh) cells exhibit influence over B-cell responses. Transfer of Th17 cells into T-cell-deficient TCR $\alpha^{-/-}$mice results in increased serum IgG titers across all measured subtypes (IgG1, IgG2a, IgG2b, and IgG3), with the strongest increases in IgG1 and IgG2b. ${ }^{9}$ Furthermore, transfer of Th17 cells induces the generation of germinal centers (GCs) in the

\footnotetext{
${ }^{1}$ Department of Microbiology and Immunology, University of Texas Medical Branch, Galveston, Texas, USA. ²Department of Pathology, University of Texas Medical Branch, Galveston, Texas, USA. ${ }^{3}$ Department of Immunology, MD Anderson Cancer Center, University of Texas, Houston, Texas, USA and ${ }^{4}$ Department of Medicine, University of Alabama at Birmingham, Birmingham, Alabama, USA. Correspondence: Y Cong (yicong@utmb.edu)
} 
spleen and draining lymph nodes, structures that are mostly lacking in the absence of $\mathrm{T}$ cells. These effects are dependent on both IL-17 and IL-21, as transfer of Th17 cells into IL-17ra ${ }^{-1-}$ or IL-21r ${ }^{-1-}$ mice do not increase the number of GCs present. Direct addition of IL-17 to B cells in vitro triggers the production of IgG2a and IgG3, whereas IL-21 induces production of IgG1, IgG2a, IgG2b, and IgG $3,{ }^{9}$ indicating that sources of IL-21 and IL17 are competent B-cell helpers in generating systemic IgG responses. The effects of IL-17 and IL-21 on IgG induction is further demonstrated in the role of IL-17 during systemic lupus erythematosus, characterized by autoreactive B cells and pathogenic autoantigen antibody production. Patients with systemic lupus erythematosus have increased serum levels of IL17, IL-21, and B cell-activating factor belonging to the TNF family, which promote survival and antibody production from autoantigen $\mathrm{B}$ cells. ${ }^{10-13}$ We recently demonstrated that intestinal Th17 cells promote secretory IgA response through IL-17 stimulation of intestinal epithelial expression of polymeric Ig receptor. ${ }^{14} \mathrm{~A}$ recent report further demonstrates that Th17 cells convert into Tfh cells in Peyer's patches and induce intestinal IgA. ${ }^{15}$ It has been shown that IL-21 can modulate B-cell differentiation by enhancing IL-4-driven IgG production $^{16}$ and transforming growth factor $\beta$ (TGF $\beta$ )-driven IgA production. ${ }^{17}$ However, whether Th17 and Tfh cell cytokines directly influence mucosal IgA production has not been fully investigated. In this report, we demonstrate that IL-21, produced by both Th17 and Tfh cells, can augment IgA responses mediated by TGF $\beta 1$ and retinoic acid (RA) in the intestine, and intestinal sources of IL-21 directly induce IgA production.

\section{RESULTS}

\section{IL-21 but not IL-17 promotes intestinal B-cell production of $\lg \mathrm{A}$}

$\mathrm{CD}^{+}{ }^{+} \mathrm{T}$ cells have an important role in the induction of IgA in the intestine, as T-cell-deficient $\operatorname{TCR} \beta \mathrm{x} \delta^{-1-}$ mice have significantly lower amounts of fecal IgA. ${ }^{18}$ Our previous work has detailed an important role for Th17 cells in the regulation of the intestinal IgA response through induction of $\mathrm{pIgR}$ expression on intestinal epithelial cells as mediated by IL17. ${ }^{14}$ Th17 cells produce high levels of IL-17, IL-21, and IL$22 .{ }^{19,20} \mathrm{~B}$ cells do not express the IL-22r, ${ }^{21,22}$ so we investigated the roles of IL-17 and IL-21 in the intestinal IgA response. Analysis of fecal IgA levels between wild-type and IL-17r ${ }^{-1-}$ mice demonstrate decreased levels of intestinal IgA (data not shown) as previously published. ${ }^{14}$ We further determined the role of IL-21 in the intestinal IgA response by analyzing IgA levels in mice deficient in IL-21 signaling. Quantification of fecal IgA from IL-21 $1^{-1-}$, IL-21r ${ }^{-1-}$ and wild-type mice revealed a significant decrease in IgA levels in the absence of IL21 signaling (Figure 1a), demonstrating that IL-21 regulates intestinal IgA production.

Given that the separate absence of both IL-17 and IL-21 resulted in deficiencies in the intestinal IgA response, we then investigated whether IL- 17 and IL-21 could directly stimulate B cells to produce IgA. We isolated splenic naive $\mathrm{IgD}^{+} \mathrm{B}$ cells and cultured them with anti- $\mu$ and CD40L for B-cell activation to

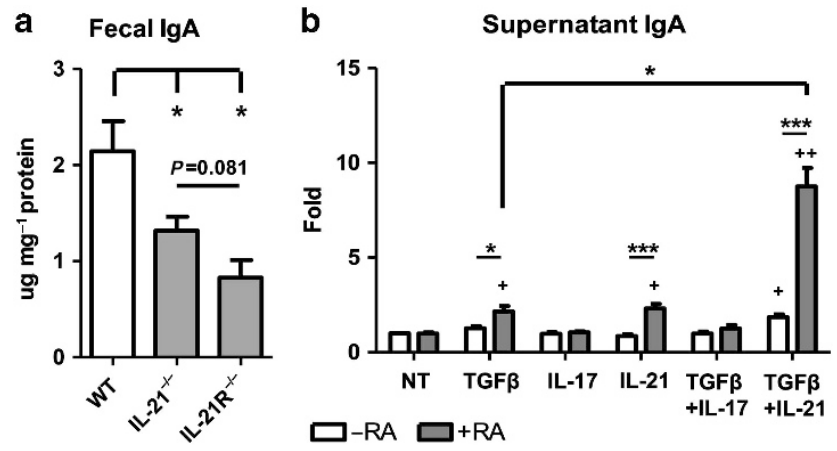

Figure 1 Interleukin (IL)-21 regulates immunoglobulin A (IgA) production in cooperation with transforming growth factor $\beta 1$ (TGF $\beta 1$ ) and/ or retinoic acid (RA). (a) Fecal pellets were collected from age-matched wild-type, IL-21 ${ }^{-1-}$, and IL-21R ${ }^{-1-} \mathrm{B} 6$ mice. IgA levels were quantified through enzyme-linked immunosorbent assay (ELISA) and normalized to total protein. $N=2$ mice per group; data are reflective of two independent experiments. ${ }^{*} P<0.05$ compared with wild-type mice. (b) Naive $\operatorname{lgD}{ }^{+} \mathrm{B}$ cells were activated with anti- $\mu\left(5 \mu \mathrm{g} \mathrm{ml}^{-1}\right)$ and anti-CD40 $\left(5 \mu \mathrm{g} \mathrm{ml}^{-1}\right)$ in the presence of TGF $\beta 1\left(5 \mathrm{ng} \mathrm{ml}^{-1}\right), \mathrm{IL}-17\left(50 \mathrm{ng} \mathrm{ml}^{-1}\right)$, IL-21 $\left(20 \mathrm{ng} \mathrm{ml}^{-1}\right)$, or RA $(1 \mu \mathrm{m})$ or a combination of TGF $\beta 1, \mathrm{IL}-17, \mathrm{IL}-21$, and/or RA. On day $5, \operatorname{IgA}$ was measured from the supernatant by ELISA. Data are reflective of six independent experiments. ${ }^{\star} P<0.05$, ${ }^{\star * \star} P<0.001$ compared between samples. ${ }^{+} P<0.05,{ }^{++} P<0.01$ compared with untreated cells.

mimic T-cell contact, together with TGF $\beta 1$ in the presence or absence of IL-17 or IL-21. IgA in the supernatant was measured by enzyme-linked immunosorbent assay after 5 days of culture. As seen in Figure 1b, addition of IL-17 did not induce IgA production in vitro, alone or in combination with TGF $\beta 1$. Addition of IL-21 alone had little effect on IgA production but moderately increased TGF $\beta 1$-induced IgA. RA, which is enriched in the intestine, has been shown to enhance B-cell IgA production as mediated by other cytokines, including TGF $\beta 1^{23}$ and IL- $6 .{ }^{24}$ To this end, we observed that addition of RA greatly enhanced IgA production in conjunction with TGF $\beta$ and IL-21. Surprisingly, IL-21 also cooperated with RA to increase IgA production in the absence of exogenous TGF $\beta 1$. Taken together, these data indicated that IL-21 is an effective Th17 cell cytokine for mediating IgA production by synergizing with RA.

\section{IL-21 augments TGF $\beta$-mediated IgA class switch recombination (CSR)}

It has been shown that IL-21 is able to modulate B-cell differentiation by enhancing IL-4-driven IgG production ${ }^{16}$ and TGF $\beta$-driven IgA production. ${ }^{17}$ We then investigated the mechanisms by which IL-21 regulates B-cell IgA production. In order for B cells to fully differentiate, activated B cells undergo CSR, by which the Ig heavy chain locus becomes rearranged and portions of the locus become looped-out and excised from the genome. The physical recombination of the Ig locus is facilitated by the enzyme activation-induced cytokine deaminase $($ Aicda $) .{ }^{25} \mathrm{~B}$ cells undergo IgA CSR after exposure to TGF $\beta 1$, and the loci for IgG, IgE, and IgM are removed from the genome. These B cells are permanently differentiated and can only produce IgA. CSR is a rapid process; however, the loopedout chromosomes stay within the cell for $24-48 \mathrm{~h}^{25}$ and 
a
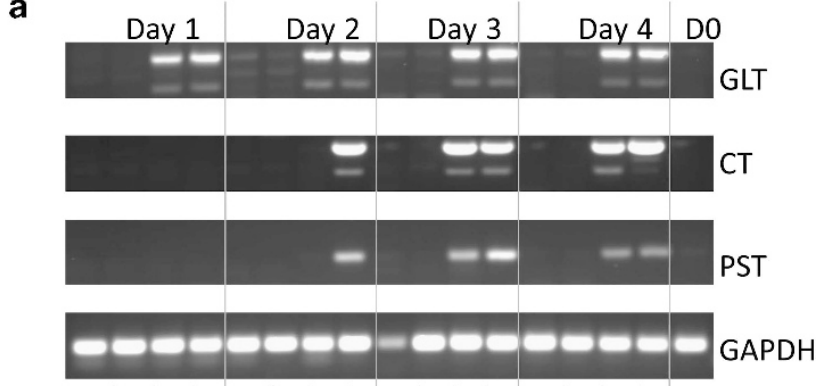

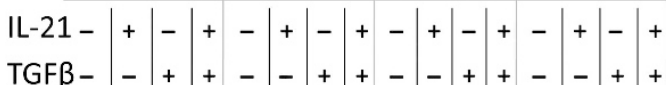

b

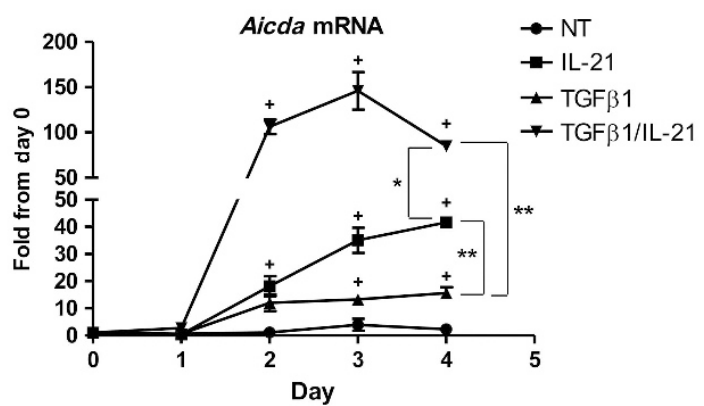

Figure 2 Interleukin (IL)-21 enhances transforming growth factor $\beta$ (TGF $\beta$ )-mediated class switching toward immunoglobulin A $(\lg A)$. Naive $\mathrm{IgD}^{+} \mathrm{B}$ cells were activated with anti- $\mu\left(5 \mu \mathrm{g} \mathrm{ml}^{-1}\right)$ and anti-CD40 $\left(5 \mu \mathrm{g} \mathrm{ml}^{-1}\right)$ in the presence of TGF $\beta 1\left(5 \mathrm{ng} \mathrm{ml}^{-1}\right)$ or IL-21 $\left(20 \mathrm{ng} \mathrm{ml}^{-1}\right)$, or a combination of TGF $\beta 1$ and IL-21. (a) RNA was collected from cultured B cells on various days during culture, and $2 \mu \mathrm{g}$ RNA was used to analyze molecular markers for IgA class switch recombination by reverse transcription-PCR (RT-PCR). CT, circular transcripts; GLT, $\alpha$ germ-line transcripts; PST, $\alpha$ postswitch transcripts. Image is representative of three independent experiments. (b) Aicda mRNA was analyzed from cells on various days during culture by RT-PCR. Aicda expression values were normalized to Gapdh expression. Data are reflective of three independent experiments. ${ }^{*} P<0.05$, ${ }^{* *} P<0.01$ compared between day 4 samples.

${ }^{+} P<0.05$ compared with untreated samples.

continue to be transcribed until they are degraded. As a result of the continued transcription, detection of these mRNAs as remaining circular transcripts (CT) via reverse transcription PCR are indicative of cells that are actively undergoing CSR to IgA-producing cells. ${ }^{25,26}$ To determine whether IL-21 can induce CSR, splenic B cells were cultured with anti- $\mu$ and CD40L. TGF $\beta 1$ and/or IL-21 were added to the cultures, and RNA was collected daily to detect when CSR began. As shown in Figure 2a, TGF $\beta 1$ immediately induced germ-line production of IgA, with CSR to IgA commencing on day 3 (CT). Transcription of IgA after CSR ( $\alpha$ postswitch transcripts) was also detectable on day 3 , in accordance with CSR induction. As expected, ${ }^{9,27}$ treatment of B cells with IL-21 alone neither induce germ-line IgA nor CSR to IgA. However, IL-21 augmented and accelerated TGF $\beta$-mediated IgA CSR as treatment with both TGF $\beta 1$ and IL-21 continued to induce IgA production and CSR. Furthermore, CSR and postclass switched IgA were detected one day earlier when IL-21 was added with TGF $\beta 1$. Analysis of Aicda mRNA, required to initiate CSR to any Ig subtype, revealed that TGF $\beta 1$ and IL-21 each induced Aicda, with TGF $\beta 1$ inducing IgA CSR and IL-21
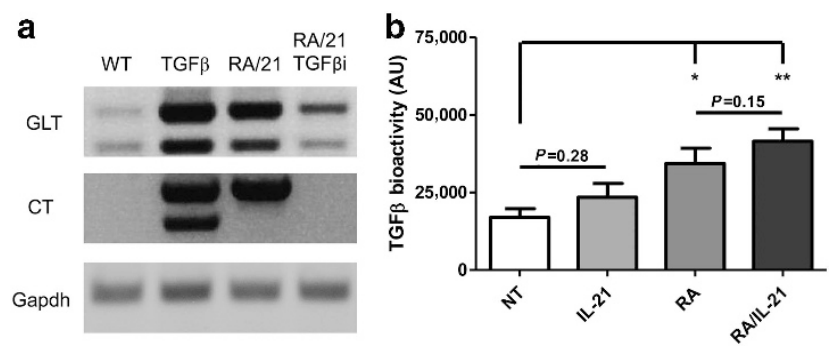

Figure 3 Interleukin (IL)-21 and retinoic acid (RA) induce class switch recombination $(C S R)$ to immunoglobulin $A(\lg A)$-secreting cells by inducing transforming growth factor $\beta$ (TGF $\beta$ ) production from $B$ cells. (a) Naive $\operatorname{lgD}{ }^{+} B$ cells were activated with anti- $\mu\left(5 \mu \mathrm{g} \mathrm{ml}^{-1}\right)$ and anti-CD40 $\left(5 \mu \mathrm{g} \mathrm{ml}^{-1}\right)$ in the presence of TGF $\beta 1\left(5 \mathrm{ng} \mathrm{ml}^{-1}\right)$ or IL-21 $\left(20 \mathrm{ng} \mathrm{ml}^{-1}\right)$ or RA (1 $\mu \mathrm{M})$ and a TGF $\beta$ receptor I inhibitor $(1 \mu \mathrm{M})$. RNA was collected from cultured B cells after 3 days, and $2 \mu \mathrm{g}$ RNA was used to analyze molecular markers for IgA CSR by reverse transcription-PCR. CT, circular transcripts; GLT, $\alpha$ germ-line transcripts. Image is representative of three independent experiments. (b) Naive $\operatorname{lgD}^{+} \mathrm{B}$ cells were activated with anti$\mu$ and anti-CD40 in the presence of IL-21 and/or RA. On day 5, supernatant was collected from cultured $B$ cells as a conditioned medium. To detect bioactive TGF $\beta$, the TGF $\beta$-reporter cell line MFB-F11 was cultured with $\mathrm{B}$-cell-conditioned medium for $24 \mathrm{~h}$. Secreted alkaline phosphatase was measured as a reflection of TGF $\beta$ bioactivity. Data are reflective of four independent experiments. ${ }^{\star} P<0.05$, ${ }^{\star *} P<0.01$ compared with conditioned medium from untreated $B$ cells.

inducing IgG CSR (Figure 2b). Interestingly, treatment with both TGF $\beta 1$ and IL-21 greatly enhanced Aicda transcription from day 2 on, correlating with the appearance of CT and postclass switched IgA transcripts seen on day 2. Collectively, our data reveal that although IL-21 itself does not facilitate IgA CSR, it potently augments and accelerates TGF $\beta$-mediated IgA CSR. In contrast, IL-17 alone neither induce Aicda nor did it enhance TGF $\beta 1$-induced Aicda (data not shown).

As RA and IL-21 also increased IgA production in the absence of exogenous TGF $\beta 1$, we next investigated how IL-21 and RA regulate IgA production. Analysis of the mRNA transcripts revealed that IL-21 and RA together were capable of inducing an overall IgA response, particularly at the germ-line transcriptional level (Figure 3a). Interestingly, we were able to detect CT in B cells treated with IL-21 and RA, without exogenous TGF $\beta 1$. Treatment of B cells with IL-21, RA, and a TGF $\beta$ receptor I inhibitor (SB505124) negated the IgA CSR process, revealing that IL-21 and RA stimulation of IgAsecreting B-cell development is still reliant upon TGF $\beta$, which could be mediated by enhancing B-cell response to TGF $\beta$ or promoting B-cell production of TGF $\beta$.

We sought to determine whether IL-21 and RA signals were able to modulate the B-cell response to TGF $\beta$. Although the naive $B$ cells continued to produce IgA in the absence of exogenous TGF $\beta$, there remained some TGF $\beta$ in the culture as a result of medium supplemented with fetal bovine serum. However, IL-21 and RA (separately or in tandem) did not increase B-cell expression of tgfbr1 or tgfbr2 (data not shown), and thus they did not influence B-cell sensitivity to TGF $\beta 1$. Our previous work has demonstrated that that RA induces dendritic cell TGF $\beta 1$ production, resulting in increased regulatory T-cell differentiation in the intestine. ${ }^{28}$ We then investigated whether IL-21 and RA could induce B-cell production of TGF $\beta$ and 
a

None
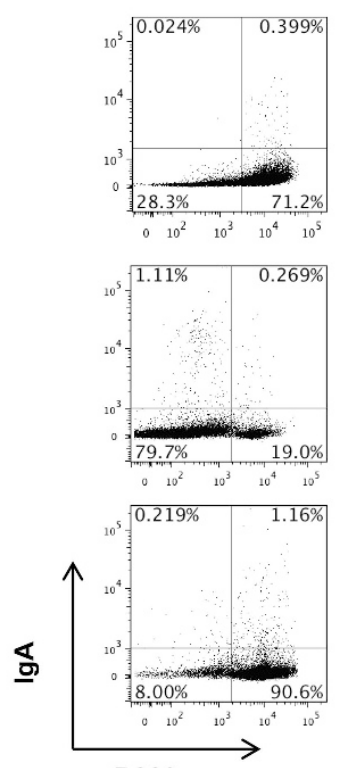

B220
Th17
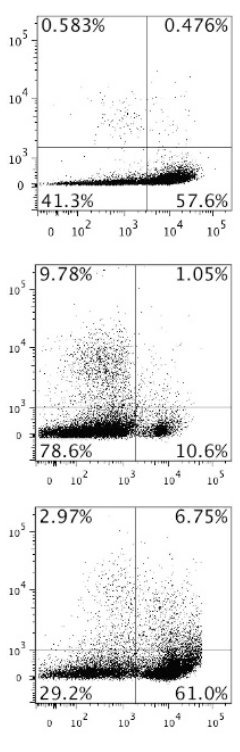

Th17 +

alL-21r
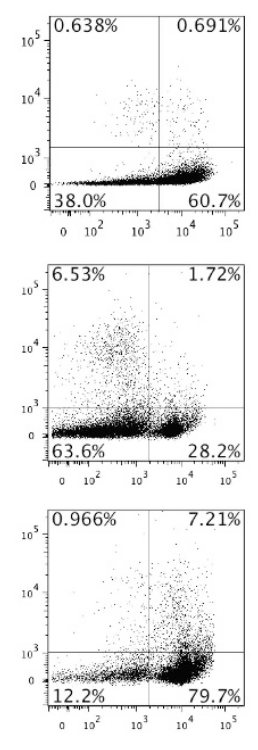

Intestinal $\lg \mathrm{A}^{+} \mathrm{PC}$

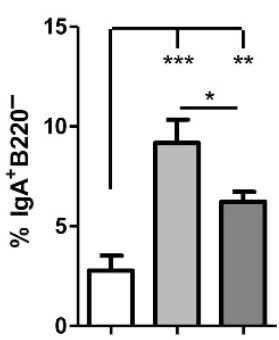

Intestinal $\lg \mathrm{A}^{+} \mathrm{B}^{220^{+}}$

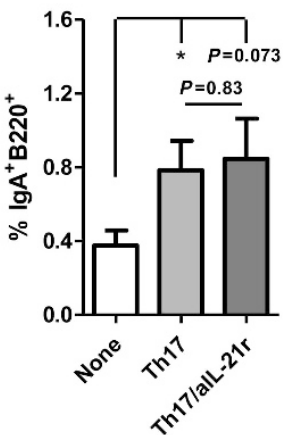

Spleen

LPL

PP b

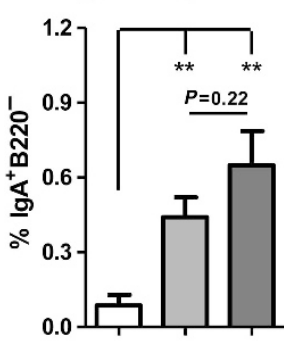

$\lg \mathrm{A}^{+} \mathrm{B220}^{+}$spleen

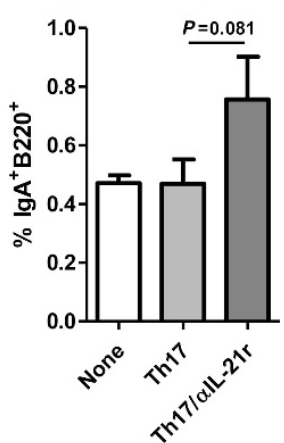

$\lg \mathrm{A}^{+} \mathrm{PC}$ spleen

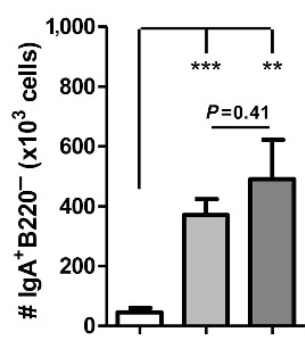

$\lg \mathrm{A}^{+} \mathrm{B220}^{+}$spleen

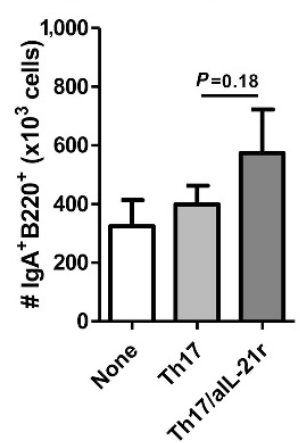

Intestinal $\lg \mathrm{A}^{+} \mathrm{PC}$

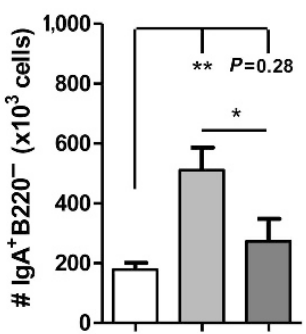

Intestinal $\lg \mathrm{A}^{+} \mathrm{B}^{220^{+}}$

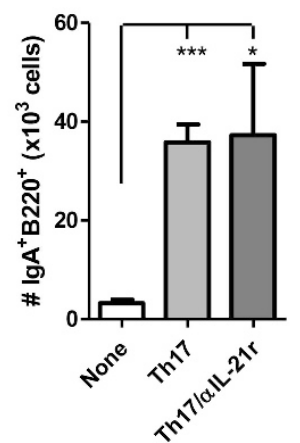

Figure 4 Transfer of CBir1 T helper type 17 (Th17) cells into TCR $\beta \times \delta^{-1-}$ mice increases immunoglobulin $\mathrm{A}(\lg \mathrm{A})^{+} \mathrm{B}$ cells in the intestine. In all, $10^{6}$ CBir1 Th17 cells were intravenously transferred into TCR $\beta \times \delta^{-1-}$ mice. (a) On day 44 post-Th17 cell transfer, expression of surface IgA on splenic, intestinal lamina propria, or Peyer's patch (PP) B cells of CBir1 Th17 cell recipients, Th17 cell recipients receiving neutralizing IL-21r (Th17 $+\alpha \mathrm{lL}-21 \mathrm{r}$ ), or control TCR $\beta \times \delta^{-1-}$ mice was determined by flow cytometry. Fluorescence-activated cell-sorted plots are representative of four mice per group. (b) IgA ${ }^{+}$ plasma cells (PCs) and mature B cells in the spleens and intestines. Bar charts reflect mean \pm s.e.m. Data reflect three independent experiments. ${ }^{\star} P<0.05,{ }^{\star \star} P<0.01,{ }^{* \star} P<0.001$ between compared samples. LPL, intestinal lamina propria lymphocytes.

therefore drive IgA CSR. Consistently, we revealed that RA has a similar effect in B cells, in that RA is able to induce TGF $\beta$ production from B cells. Although IL-21 has little effect on TGF $\beta$ induction, it appears to promote RA-induced TGF $\beta$ production (Figure $3 \mathbf{b}$ ). Appropriately, the induction of TGF $\beta$ by RA, and synergism with IL-21 is sufficient to drive IgA production in the absence of exogenous TGF $\beta 1$.
Transfer of Th17 cells promote $\lg \mathrm{A}^{+} \mathrm{B}$-cell development in the intestinal lamina propria but not in the spleen of $\operatorname{TCR} \beta \times \delta^{-1-}$ mice

Thus far, our results in vitro have demonstrated that IL-21 promotes B-cell development towards IgA production. As Th17 cells produce IL-21, in addition to IL-17, we then transferred Th17 cells into TCR $\beta \mathrm{x} \delta^{-/-}$mice, which contain B 

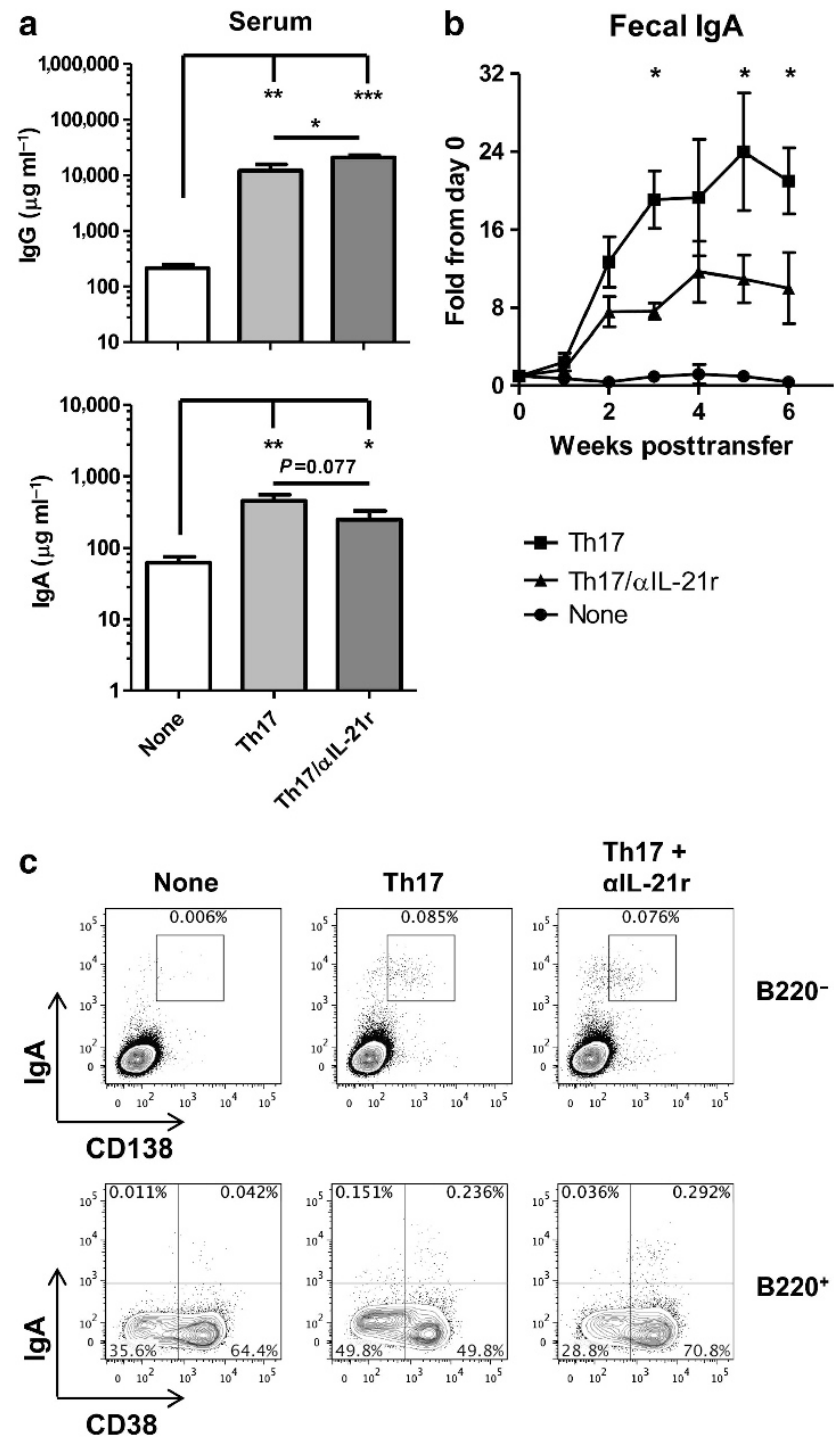

$\mathrm{B} 220^{+}$

Figure 5 Transfer of CBir1 Thelper type 17 (Th17) cells into TCR $\beta \times \delta^{-1-}$ mice increases both systemic and intestinal immunoglobulin $A(\operatorname{IgA})$ production. (a) On day 44 post-Th17 cell transfer, IgG and IgA in the serum was measured by enzyme-linked immunosorbent assay (ELISA).

${ }^{\star} P<0.05,{ }^{* \star} P<0.01,{ }^{* \star *} P<0.001$ (b) Fecal pellets were collected from Th17 cell recipients during the course of the experiment. IgA levels were quantified through ELISA and normalized to total protein. Changes in the expression over time are expressed as a fold change from individuals pretransfer. $N=4$ mice per group, from three independent experiments. ${ }^{\star} P<0.05$ as compared with anti-interleukin (IL)-21r group. (c) Intracellular IgA production was measured from total bone marrow cells of CBir1 Th17 cell recipients, Th17 cell recipients receiving neutralizing IL-21r $(\mathrm{Th} 17+\alpha \mathrm{lL}-21 \mathrm{r})$, or control TCR $\beta \times \delta^{-1-}$ mice by flow cytometry. Fluorescence-activated cell-sorted plots are representative of four mice per group.

cells but lack $\mathrm{T}$ cells, to determine whether they can affect intestinal $\operatorname{Ig} \mathrm{A}^{+} \mathrm{B}$-cell development and B-cell IgA production in vivo, and whether IL-21 was required for their action. We generated Th17 cells from microbiota antigen CBir1-specific T-cell receptor (TCR) transgenic mice ${ }^{29}$ in vitro and transferred them into $\operatorname{TCR} \beta \mathrm{x} \delta^{-1-}$ mice and treated them with a neutralizing antibody against the IL-21 receptor (IL-21r).
Recipient mice were killed 44 days after transfer, and frequencies of $\operatorname{IgA}^{+} \mathrm{B}$ cells were measured in the spleen and intestines. Antibody levels were also measured from feces and serum and compared with naive $\operatorname{TCR} \beta \mathrm{x} \delta^{-1-}$ mice. Transfer of Th17 cells did not significantly increase populations of $\mathrm{IgA}^{+} \mathrm{B} 220^{+}$cells in the spleen; however, both frequencies and the total population of $\mathrm{IgA}^{+} \mathrm{B}_{2} 20^{-}$plasma cells were increased in the spleen (Figure 4a,b). Blockade of IL-21 signaling did not affect the levels of both $\operatorname{IgA}^{+} \mathrm{B}_{220}{ }^{+}$and B220 ${ }^{-}$cells. Analysis of intestinal B cells revealed greater numbers of $\operatorname{IgA}^{+} \mathrm{B}$ cells in the lamina propria of intestines (Figure 4a,b) after Th17 cell transfer. Within the intestinal lamina propria, the levels of both $\operatorname{IgA}^{+} \mathrm{B}_{2} 20^{+}$and $\mathrm{B} 220^{-}$ plasma cells were significantly increased. Notably, blockade of IL-21 primarily decreased populations of IgA ${ }^{+}$plasma cells but had no discernible effect on IgA ${ }^{+} \mathrm{B}_{220^{+}}$cells. This remained consistent with B-cell populations within the Peyer's patches, as Th17 cell transfer increased IgA production from $\mathrm{B}_{22} 20^{+}$and B220 - cells; however, blockade of IL-21 reduced IgA ${ }^{+}$plasma cell populations without affecting $\mathrm{B}_{22}{ }^{+}$cells. Consistently, transfer of Th17 cells increased serum IgA when compared with naive $\mathrm{TCR} \beta \mathrm{x} \delta^{-1-}$ mice (Figure $\mathbf{5 a}$ ), which was slightly attenuated by blockade of IL-21r. Levels of IgG in the serum also increased significantly after Th17 cell transfer. Notably, blockade of IL-21 increased serum IgG, likely indicating a role for IL-21 in the switching from IgG to IgA production (Figure 5a). Th17 cells were capable of inducing strong intestinal IgA responses as measured from 2 weeks after Th17 cell transfer (Figure $\mathbf{5 b}$ ), which is consistent with previous reports. ${ }^{14,15}$ Blockade of IL-21r decreased the IgA levels in the feces, consistent with the decrease in IgA-secreting plasma cells. Given that we used CBir1 Tg Th17 cells that respond to the immunodominant bacterial flagellin $\mathrm{CBir} 1,{ }^{18}$ the transferred $\mathrm{T}$ cells would become activated and exhibit effector function after migrating to the intestine and encountering the intestinal antigens. That may in part explain why we observe that the expansion in $\mathrm{B}_{22} 20^{+}$cells primarily occurs in the intestine. The resulting plasma cells appear to re-enter circulation in the spleen. Furthermore, $\mathrm{IgA}^{+}$cells were found in the bone marrow of Th17 cell recipients, whereas the bone marrow of naive TCR $\beta \times \delta^{-1-}$ mice did not contain IgA-producing cells. $\mathrm{IgA}^{+} \mathrm{B} 220^{-} \mathrm{CD} 138^{+}$plasma cells migrated into or were formed in the bone marrow after Th17 cell transfer. We also found a population of $\operatorname{IgA}^{+} \mathrm{B} 220^{+} \mathrm{CD} 38^{+}$cells in the bone marrow, which could be partially comprised of memory $B$ cells. Blockade of IL-21 did not have an effect on $\operatorname{IgA}^{+}$B-cell populations in the bone marrow (Figure 5c). Although IL-21 was important for plasma cell generation in the periphery and the intestines, IL-21 did not contribute to plasma cell populations in the bone marrow, possibly indicating that bone marrow plasma cells were generated in the periphery and entered the bone marrow, or the neutralizing antibodies were limited in penetrating the bone marrow. ${ }^{30}$ Consistently, the increased levels of IgA results in both increased secretion into the intestinal lumen, as well as increased circulation in the serum, to which IL-21 contributes. 

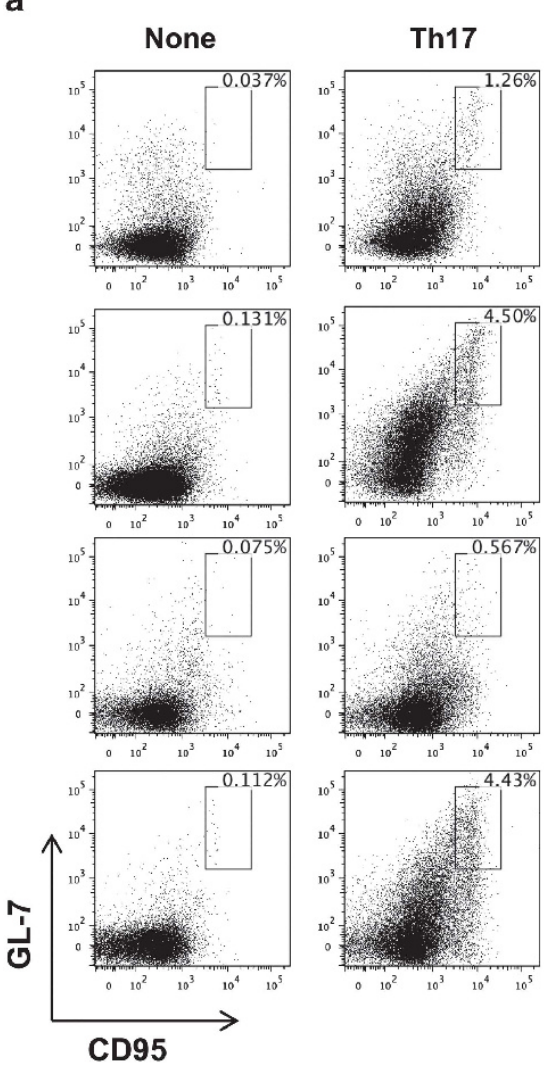

Th17
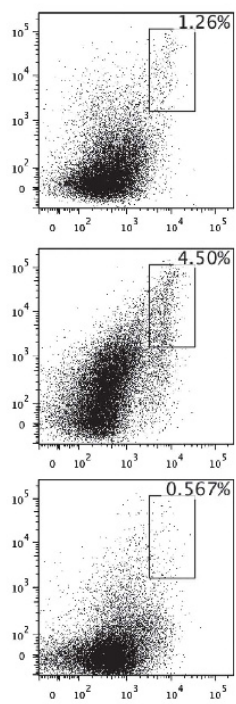

Th17 +

alL-21r
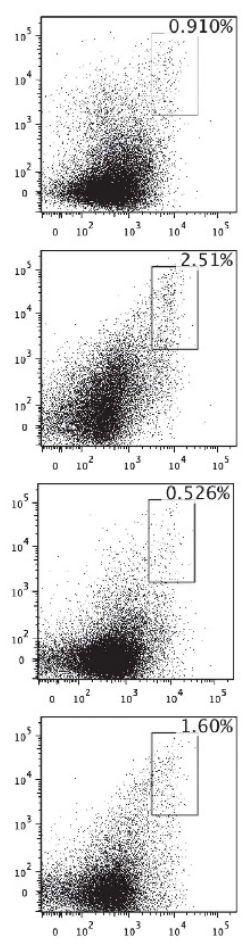

Spleen

c

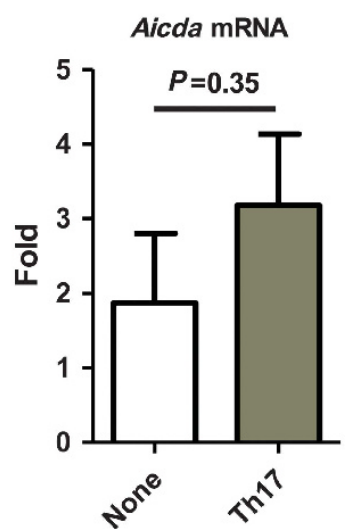

LPL

PP

b
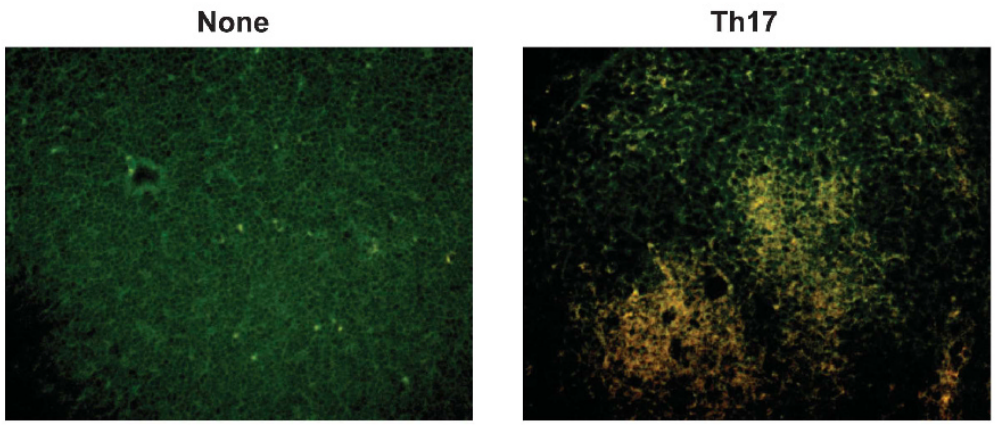

Figure 6 Transfer of CBir1 Thelper type 17 (Th17) cells into TCR $\beta \times \delta^{-1-}$ mice induces germinal center formation in the intestinal lymphoid tissues. In all, $10^{6}$ CBir 1 Th17 cells were intravenously transferred into TCR $\beta \times \delta^{-1-}$ mice. (a) On day 44 post-Th17 cell transfer, the expression of germinal center markers GL-7 and CD95 on splenic, mesenteric lymph node (MLN), intestinal lamina propria, or Peyer's patch (PP) B220 ${ }^{+}$cells of CBir1 Th17 cell recipients, Th17 cell recipients receiving neutralizing interleukin (IL)-21r (Th17 + $\alpha \mathrm{lL}-21 \mathrm{r}$ ), or control TCR $\beta \times \delta^{-1-}$ mice was determined by flow cytometry. Fluorescence-activated cell-sorted plots are representative of four mice per group. (b) Immunofluorescence image of PP from control TCR $\beta \times \delta^{-1-}$ mice or CBir1 Th17 cell recipients with $\times 20$ objective. Germinal center formation was analyzed by staining for GL-7-AlexaFluor 594 and B220-fluorescein isothiocyanate. (c) RNA was collected from ileal tissue on day 44 post-Th17 cell transfer from CBir1 Th17 cell recipients or control TCR $\beta \times \delta^{-\prime-}$ mice, and Aicda mRNA was analyzed by reverse transcription-PCR. Data are reflective of four mice per group from three independent experiments. LPL, intestinal lamina propria lymphocytes.

GC reactions are critical for T-dependent antibody responses. It has been shown that IL-17 and IL-21 nonredundantly contribute toward GC formation within the lymphoid tissues. ${ }^{9}$ Within naive TCR $\beta \mathrm{x} \delta^{-1-}$ mice, we found no evidence of germinal B cells based on co-expression of GL7 and CD95. GC B cells were increased after transfer of Th17 cells (Figure 6a). We found the highest incidences of GCs within the mesenteric lymph node and Peyer's patches. With the associated increase in GC B cells (Figure 6a), we observed that structured GCs had developed in the Peyer's patches of
Th17 cell recipients (Figure 6b). Consistent with previously described roles for IL-21, ${ }^{9,27}$ we found that neutralizing IL-21r decreased the frequencies of GC B cells in both the mesenteric lymph node and Peyer's patches; however, frequencies remained higher than those found in naive $\operatorname{TCR} \beta \mathrm{x} \delta^{-1-}$ mice (Figure 6a). B cells in the intestinal lamina propria also reflected a small number of GC B cells; however, we were unable to detect active IgA class switching in the intestinal tissue. Further, Aicda expression was not significantly changed after Th17 cell transfer (Figure 6c). Collectively, these data indicated 
a
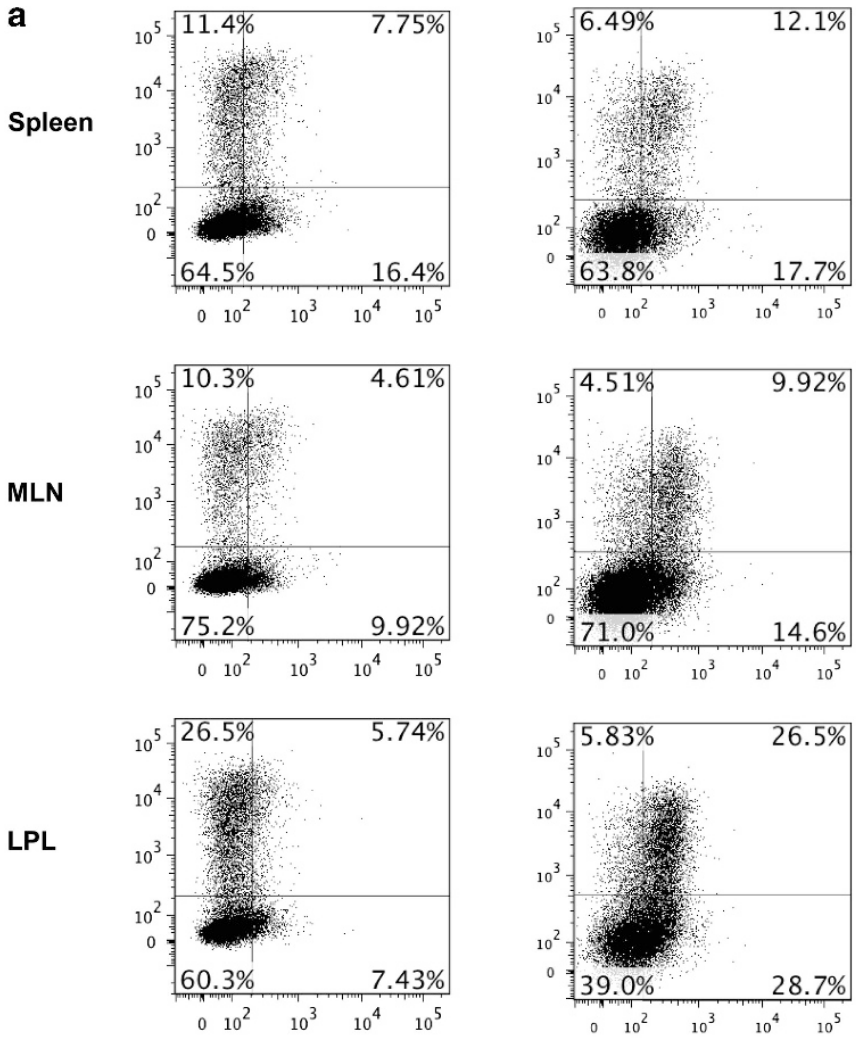

LPL
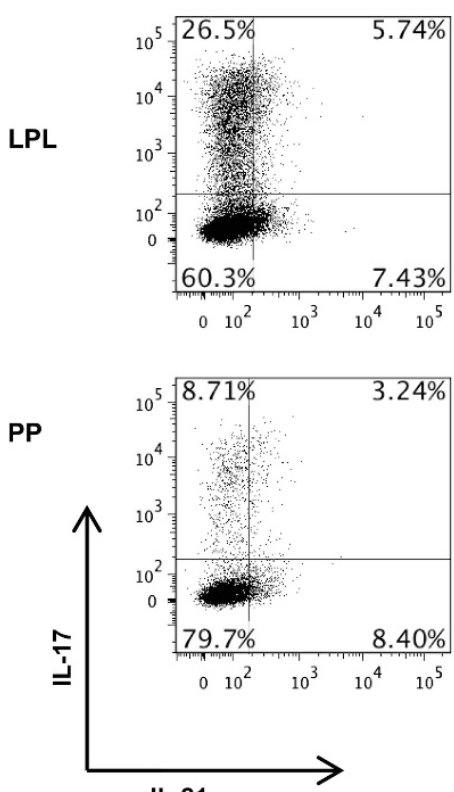

IL-21

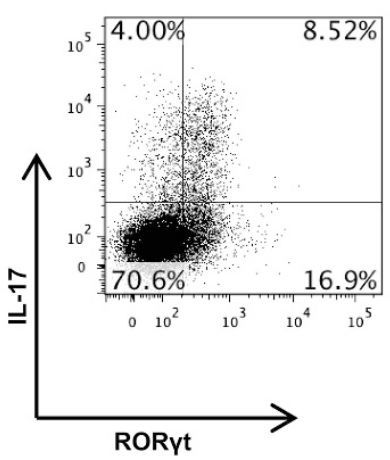

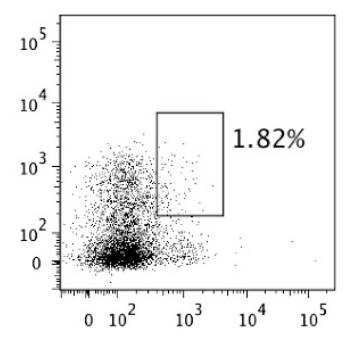

b
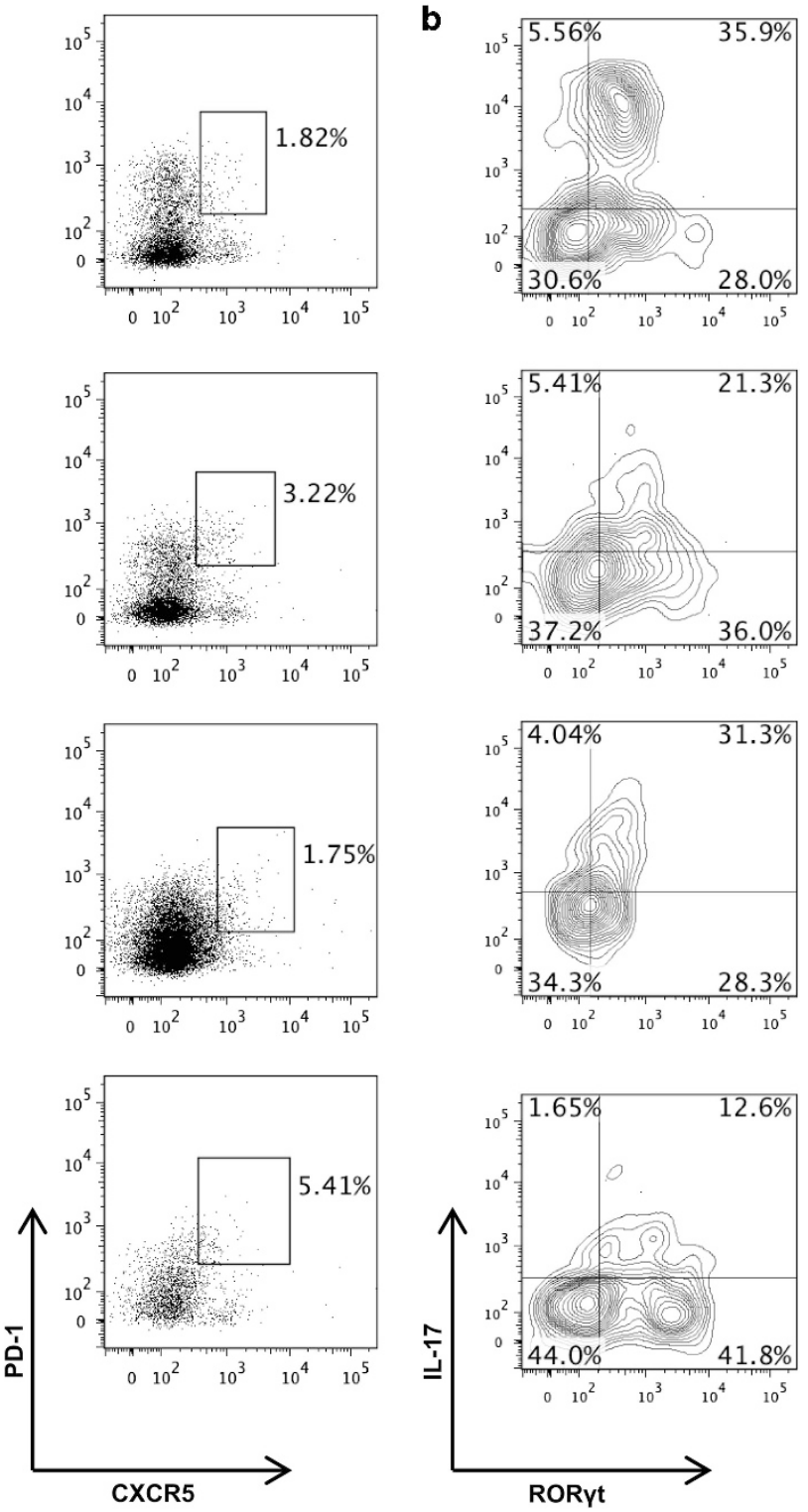

Figure 7 Transferred CBir1 Thelper type 17 (Th17) cells into TCR $\beta \times \delta^{-1-}$ mice retain interleukin (IL)-17 and retinoic acid-related orphan receptor $\gamma \mathrm{t}$ (ROR $\gamma \mathrm{t}$ ) expression. In all, $10^{6} \mathrm{CBir} 1 \mathrm{Th} 17$ cells were intravenously transferred into TCR $\beta \times \delta^{-1-}$ mice. (a) On day 44 post-Th17 cell transfer, analysis of IL-17, IL-21, ROR $\gamma \mathrm{t}$, PD-1, and C-X-C motif chemokine receptor 5 (CXCR5) expression on the spleen, mesenteric lymph node (MLN), intestinal lamina propria, or Peyer's patch (PP) CD4 T cells of CBir1 Th17 cell recipients was determined by flow cytometry. (b) Analysis of IL-17 and ROR $\gamma t$ expression from PD-1 ${ }^{+}$CXCR5 ${ }^{+}$CD4 T cells of CBir1 Th17 cell recipients was determined by flow cytometry. Fluorescence-activated cell-sorted plots are representative of four mice per group. LPL, intestinal lamina propria lymphocytes.

that the intestinal lamina propria was not the primary site for IgA induction.

Follicular T cells are also a substantial source of IL-21 and are abundantly present in the lymphoid tissues. It has been recently discovered that Th17 cells can undergo conversion into Tfh in the Peyer's patches, where they produce IL-21 and drive IgA responses. ${ }^{15}$ We therefore investigated whether our transferred Th17 cells were converting into Tfh in the intestines. We found that the transferred Th17 cells retained IL-17 and retinoic acid-related orphan receptor $\gamma \mathrm{t}(\mathrm{ROR} \gamma \mathrm{t})$ expression throughout the spleen and intestines, including the Peyer's patches. Notably, the intestinal lamina propria contained the highest populations of Th17 cells (Figure 7a). Many of the transferred cells also expressed IL-21, either independently or in tandem with IL-17. Few of the transferred cells co-expressed programmed cell death protein 1 (PD-1) and C-X-C motif chemokine receptor 5 (CXCR5), the characteristic surface markers of Tfh cells; however, those cells also retained IL-17 and ROR $\gamma$ t expression (Figure 7b). Consistent with the previous report, ${ }^{15}$ the Peyer's patches had the highest frequencies of transferred cells expressing Tfh markers; however, these cells did not completely lose IL-17 production. It is notable that the Peyer's patches had the overall lowest frequency of $\mathrm{IL}-17^{+}$cells. 

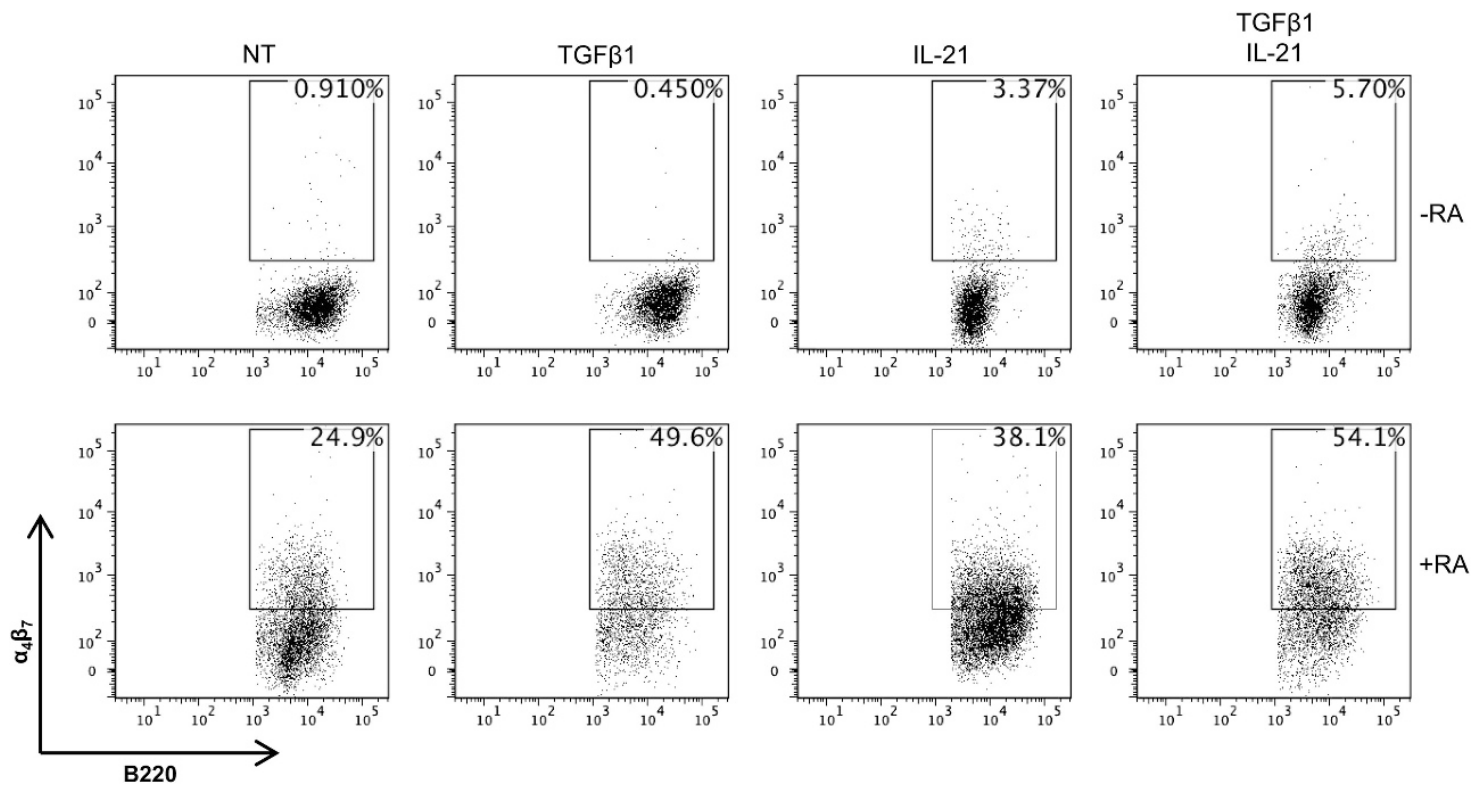

Figure 8 Interleukin (IL)-21 induces mucosal homing markers alone and in synergism with transforming growth factor $\beta 1$ (TGF $\beta 1$ ) and/or retinoic acid (RA). Naive IgD ${ }^{+}$B cells were activated with anti- $\mu\left(5 \mu \mathrm{g} \mathrm{ml}^{-1}\right)$ and anti-CD40 $\left(5 \mu \mathrm{g} \mathrm{ml}^{-1}\right)$ and cultured with TGF $\beta 1\left(5 \mathrm{ng} \mathrm{ml}^{-1}\right)$ and IL-21 $\left(20 \mathrm{ng} \mathrm{ml}^{-1}\right)$, alone or in combination, with or without RA $(1 \mu \mathrm{m})$. On day $5, \alpha_{4} \beta_{7}$ was measured by flow cytometry. Fluorescence-activated cell-sorted plots are representative of three independent experiments. NT, no treatment.

\section{IL-21 induces mucosal homing on B cells}

It has been shown that RA is able to induce the expression of homing molecules on lymphocytes to migrate to the intestinal tract. $^{28,31}$ We then questioned whether IL-21 could synergize with RA to influence B-cell mucosal homing through induction of $\alpha_{4} \beta_{7}$, thus concentrating to Th17 cell induction of intestinal IgA production. Ligation of $\alpha_{4} \beta_{7}$ on lymphocytes with mucosal addressin cell adhesion molecule 1 on endothelial vessels results in lymphocyte migration into the intestinal tract. We cultured splenic B cells with anti- $\mu$ and CD40L in the presence or absence of TGF $\beta 1$ and IL-21, alone or in combination, with or without RA to determine whether Th17 cell cytokines could induce B-cell expression of $\alpha_{4} \beta_{7}$. Five days after culture, cells were analyzed for $\alpha_{4} \beta_{7}$ expression via fluorescence-activated cell sorter. As expected, RA was able to induce $\alpha_{4} \beta_{7}$ expression, which was enhanced with TGF $\beta 1$ (Figure 8). Interestingly, IL21 alone was able to induce $\alpha_{4} \beta_{7}$ expression, which was enhanced with both TGF $\beta 1$ and RA. Although the synergy between IL-21 and RA was not quite to the degree as TGF $\beta 1$ and RA, the combination of all three molecules resulted in optimal $\alpha_{4} \beta_{7}$ expression, concomitant with IgA production as seen in Figure 1b. Notably, IL-17 had no visible effect on $\alpha_{4} \beta_{7}$ induction, both alone and in conjunction with RA (data not shown). These data indicate that IL-21 contributes to mucosal homing in addition to IgA production in conjunction with TGF $\beta 1$ and RA.

\section{DISCUSSION}

The gastrointestinal tract exists in a mutualistic relationship with the commensal flora within. Multiple mechanisms have evolved to regulate and conserve homeostasis between the immune system and microbiota. The intestines act as a natural reservoir for IgA-producing B cells, where they are critical for maintaining intestinal homeostasis by containing the vast population of commensal bacteria. Our data demonstrated that Th17 cells and their cytokine IL-21 in the intestine strongly promote intestinal IgA production by promoting differentiation of B cells to IgA-secreting cells. Furthermore, IL-21 can influence B cells to migrate into the intestine, where they can continue to differentiate into IgA-secreting cells.

Regulatory T, Th17 and Tfh cells have all been shown to promote the IgA response in the intestine. ${ }^{14,15,18}$ Both Th17 and Tfh cells produce IL-17A and IL-21, ${ }^{19,32}$ cytokines that are important for establishing GC architecture and thus the humoral response. Further, IL-21 induces B cells to undergo CSR and produce large amounts of IgG. ${ }^{9}$ TGF $\beta$ can override IL21-mediated CSR to IgG in favor of class switching to IgA in mucosal tissues. ${ }^{27}$ IL-21 has also been described to have a number of pro-B-cell effects, which may contribute to increasing IgA production, particularly during $\mathrm{T}$-dependent antibody responses. Both RA and IL-21 promote overall B-cell proliferation, ${ }^{33-35}$ as well as selected proliferation of TGF $\beta$ mediated IgA ${ }^{+}$cells. $^{23,27}$ In our current study, our results indicate that IL-21 is a potent inducer of CSR, as indicated by Aicda transcription and, when combined with TGF $\beta 1$, results in highly specific and accelerated induction of CSR to promote IgA-secreting $B$ cells. It remains notable that $\mathrm{RA}$ is required to achieve optimal IgA induction from IL-21-treated B cells in vitro. Furthermore, it is likely that IL-21 from Th17 cells synergizes with physiological RA and TGF $\beta$ to drive intestinal IgA production in vivo. This may indeed help to explain the mechanism by which the intestinal environment is so favorable for $\mathrm{IgA}^{+} \mathrm{B}$ cells. As described previously, the intestinal environment is rich in molecular cues, including TGF $\beta$ and RA, 
to promote IgA production and differentiation. As such, our data further reveal that, in the intestinal environment with high levels of TGF $\beta$ and RA, Th17 and Tfh cell production of IL-21 is capable of inducing strong $\operatorname{Ig} \mathrm{A}^{+} \mathrm{B}$-cell differentiation and $\operatorname{IgA}$ production from $B$ cells.

It is interesting to note that IL-21 and RA are capable of inducing IgA production in the absence of exogenous TGF $\beta 1$ (Figure 1b). Our previous work has detailed an important role for RA in the maintenance of the intestinal regulatory T-cell population. ${ }^{28}$ Intestinal dendritic cells are able to produce TGF $\beta$ after exposure to RA, which in turn induces Foxp3 expression in $\mathrm{CD} 4{ }^{+} \mathrm{T}$ cells and promotes regulatory T-cell differentiation. As shown in Figure 3b, RA also stimulates B cells' production of TGF $\beta$. As B cells have already been described to have regulatory roles through production of IgA and IL-10, ${ }^{36}$ our finding broadens their regulatory roles, specifically that B cells are capable of directing their own differentiation into IgA-secreting cells. Although IL-21 alone does not induce TGF $\beta$ production from B cells, it appears to promote RA-induced TGF $\beta$ production, which is consistent with the role of IL-21 in promoting IgG responses rather than IgA. The observation that IL-21 and RA can cooperate in the regulation of B-cell homing to intestines through $\alpha_{4} \beta_{7}$ suggests that Th17 and Th cells can indirectly regulate the development of IgA ${ }^{+} \mathrm{B}$ cells outside of the intestinal tract. Environments such as the bone marrow are rich in RA and IL-2 $1^{28,37,38}$ and may influence naive B cells from the bone marrow to migrate en masse to the intestines, where the environment is ripe for the induction of $\operatorname{IgA}^{+} \mathrm{B}$ cells. Interestingly, IL-17 and IL-21 differentially regulate intestinal IgA response in a cooperative manner.

The primary observation that IL-21 can promote $\operatorname{IgA}^{+} \mathrm{B}$ cells appears to occur primarily in the intestinal tract. After transferring Th17 cells into naive $\mathrm{TCR} \beta \mathrm{x} \delta^{-1-}$ mice, we observed a strong increase in $\operatorname{IgA}^{+}$cells in the periphery and intestines; however, blockade of IL-21 only decreased IgA ${ }^{+}$ cells in the intestines. Accordingly, blockade of IL-21 led to a decrease in fecal IgA, while it did not significantly decrease serum IgA. This indicates that: (1) IL-21 augments the favorable environment for promoting $\operatorname{IgA}$ responses in the intestine; and (2) IL-21 may provide an important switch for B cells to produce IgA rather than IgG. Previous reports have indicated that Th17 cells produce IL-21 and support IgA production only after conversion into Tfh cells ${ }^{15}$ in the Peyer's patches. However, we found that our Th17 cells retained IL-17 and ROR $\gamma \mathrm{t}$ expression 7 weeks after transfer. Transferred cells also expressed IL-21, while lacking PD-1 and CXCR5 coexpression, suggesting limited conversion to $\mathrm{Tfh}$ cells. Although the Th17-to-Tfh conversion described by Hirota et al. ${ }^{15}$ was observed after 3 months, we found few PD-1/ CXCR5 co-expressing cells in the Peyer's patches after 7 weeks. It remains possible that Th17 reprogramming is an extended process as the Peyer's patches contained fewer IL- $17^{+}$cells than those in the lamina propria or mesenteric lymph node; however, we observed an increase in fecal IgA within 2 weeks after Th17 cell transfer, indicating that Th17 cells are competent in supporting IgA production.
Although TGF $\beta 1$ is required for CSR to IgA, a number of other factors can facilitate and modify IgA production or IgA ${ }^{+}$ cell differentiation. Previous studies have indicated that TGF $\beta$ can also induce IgG2b production; however, IL-21 appears to inhibit IgG2b production and skews toward IgA class switching. ${ }^{17}$ Although our results concur on the final differentiation pattern of IgA ${ }^{+} \mathrm{B}$ cells, we present a more rapid and efficient differentiation pattern. The increased robustness of our IL-21 treatment may be a result of the differing activation strategies; Seo et al. ${ }^{17}$ utilized T-independent activation via LPS, whereas our experiments used anti-CD40 and anti- $\mu$ antibodies in order to focus on a T-dependent mechanism. As such, our results remain consistent with observations made in human mucosal tissues, such that IL-21 can greatly increase activation-induced cytidine deaminase and IgA production in conjunction with TGF $\beta$ treatment. ${ }^{27}$ Previous evidence has demonstrated that IgA class switching primarily occurs in the Peyer's patches but can occur in the intestinal lamina propria. ${ }^{3}$ These studies revealed that both $\mathrm{T}$-dependent and $\mathrm{T}$-independent responses could occur in the intestinal lamina propria of normal mice and humans. ${ }^{39,40}$ Although we observed the expression of Aicda in the intestines of naive TCR $\beta \mathrm{x} \delta^{-1-}$ mice, the expression was neither enhanced by the presence of Th17 cells nor was the genetic evidence of IgA class switching detected, despite the high numbers of $\operatorname{IgA}^{+}$plasma cells in the lamina propria.

In summary, our current study demonstrates that IL-21, which is produced by Th17 and Tfh cells that are particularly enriched in the intestinal lamina propria, promote $\operatorname{IgA}^{+} \mathrm{B}$-cell differentiation and IgA production in the intestinal environment that contains high levels of TGF $\beta$ and RA. IL-21 directly induces B-cell IgA CSR to promote IgA-secreting B cells and B-cell IgA production, whereas IL-17 stimulates pIgR expression in epithelial cells, thereby enhancing IgA translocation into the intestinal lumen. Thus IL-21 and IL-17 coordinately regulate intestinal IgA response to microbiota.

\section{MATERIALS AND METHODS}

Mice. TCR $\beta \mathrm{x} \delta^{-/-}$mice were obtained from Jackson Laboratory (Bar Harbor, ME). CBir1 flagellin-specific TCR transgenic (CBir1-Tg) mice were maintained in the Animal Facilities at University of Texas Medical Branch. All experiments were reviewed and approved by the Institutional Animal Care and Use Committees of the UTMB and the MD Anderson Cancer Center. All the mice strains were bred in the UTMB animal facility and housed together from 3 weeks of age. IL$21^{-1-}$ and IL-21r ${ }^{-1-}$ mice ${ }^{41}$ were maintained at the Animal Facilities at MD Anderson Cancer Center. All mice are bred onto the C57BL/6 background and contain SFB as verified via PCR. Eight-to12 -week-old mice were used for all experiments.

Antibody and reagents. The following antibodies were used for flow cytometry: PE-IL-17 A (TC11-18H10.1), FITC-B220 (RA3-6B2), PE$\alpha_{4} \beta_{7}$ (DATK32), FITC-CD4 (RM4-5), PE/Cy7-CD38 (90), APCCD138 (281-2), and PE/Cy7-PD-1 (29 F.1A12) were purchased from Biolegend (San Diego, CA); APC-ROR $\gamma \mathrm{t}$ (B2D), APC-GL-7, and eFluor450-Streptavidin were from eBioscience (San Diego, CA); Brilliant Violet 421-CD95 (Jo2) and biotinylated CXCR5 (2G8) were from BD Biosciences (San Diego, CA); recombinant mouse IL-21 R human FC chimera was from R\&D Systems (Minneapolis, MN); AlexaFluor 647 anti-human IgG FC $\gamma$ (polyclonal) was from Jackson ImmunoResearch Laboratories (West Grove, PA) and PE-IgA 
(polyclonal) was from Southern Biotechnology (Birmingham, AL). Intracellular permeabilization was performed with the Foxp3 Perm/ Fix Kit from eBioscience. Live cells were gated using Live/Dead Fixable Dead Cell Stain Kit from Life Technologies (Carlsbad, CA). Mouse recombinant IL-6 and human recombinant IL-17A and TGF $\beta 1$ were purchased from R\&D Systems. Recombinant IL-21 was purchased from eBioscience. Antibody against IL-21r (4A9) was from BioXCell (West Lebanon, NH). Antibodies against IgA and IgD were purchased from Kirkegaard \& Perry Labs (Gaithersburg, MD) and Southern Biotechnology. Anti- $\mu$ was purchased from Jackson ImmunoResearch Laboratories. All-trans-RA, TGF $\beta$ receptor I inhibitor SB505124, and collagenase IV were purchased from Sigma-Aldrich (St Louis, MO). Anti-biotin microbeads from Miltenyi (San Diego, CA) were used to sort naive $\operatorname{IgD}^{+} \mathrm{B}$ cells.

Polarization of Th17 cells. CD ${ }^{+}$T cells were isolated from the spleens of CBir1 Tg mice using anti-mouse CD4-magnetic beads (GK1.5, BD Biosciences) as previously described. ${ }^{18}$ To polarize Th17 cells, CBir1-Tg $\mathrm{CD}^{+}{ }^{+} \mathrm{T}$ cells were cultured with $10 \mathrm{ng} \mathrm{ml}^{-1} \mathrm{TGF} \beta 1,20 \mathrm{ng} \mathrm{ml}^{-1} \mathrm{IL}-6$, $10 \mu \mathrm{g} \mathrm{ml}^{-1}$ anti-IFN $\gamma$ (XMG1.2, BioXCell), and $10 \mu \mathrm{g} \mathrm{ml}^{-1}$ anti-IL-4 (11B11, BioXCell) with irradiated splenic allophycocyanin. ${ }^{29}$

Fecal pellet preparation. Fecal pellets were homogenized in phosphate-buffered saline containing $0.04 \mathrm{mg} \mathrm{ml}^{-1}$ soybean trypsin inhibitor, $20 \mathrm{~mm}$ EDTA, and $2 \mathrm{~mm}$ phenylmethanesulfonylfluoride and centrifuged to remove bacteria and insoluble debris as described previously. $^{42}$

Enzyme-linked immunosorbent assay. Ninety-six-well plates (Nunc, Waltham, MA) were coated with $1 \mu \mathrm{g} \mathrm{ml}^{-1}$ anti-IgA (Kirkegaard \& Perry Labs) overnight at $4{ }^{\circ} \mathrm{C}$, blocked in phosphate-buffered saline with $1 \%$ bovine serum albumin, and incubated with sera or fecal pellets for $2 \mathrm{~h}$. After washing, adherent antibodies were detected by biotinylated anti-IgA or anti-IgG, followed by horseradish peroxidaselabeled streptavidin. Plates were developed using 3,3',5,5'-trimethylbenzene and analyzed at $450 \mathrm{~nm}$.

Intestinal lamina propria isolation. As described previously, ${ }^{18}$ intestines were removed, and the Peyer's patches were excised. Intestines were sliced and incubated with $50 \mathrm{~mm}$ EDTA to remove epithelial cells. Intestines were then digested by collagenase IV. Liberated cells were resuspended in 40\% Percoll and overlaid onto 70\% Percoll. The interface containing lymphocytes was collected. Lymphocytes were directly stained (for B cells) or restimulated with phorbol myristate acetate $\left(50 \mathrm{ng} \mathrm{ml}^{-1}\right)$, ionomycin $\left(750 \mathrm{ng} \mathrm{ml}^{-1}\right)$, and monensin for $2 \mathrm{~h}$ (for $\mathrm{T}$ cells) before staining for flow cytometry.

TGF $\beta$ bioassay. As described previously, ${ }^{28}$ MFB-F11 cells are embryonic fibroblasts from $T g f b 1^{-/-}$mice that are stably transfected with a reporter plasmid consisting of TGF $\beta$-responsive SMADbinding elements coupled to a secreted alkaline phosphatase reporter gene. Secreted alkaline phosphatase activity shown as chemiluminescence units was measured using the Great EscApe SEAP Chemiluminescence Kit 2.0 (Clontech, Mountain View, CA), following the manufacturer's instructions and represents biologically active TGF $\beta$ activity.

Quantitative real-time/reverse transcription PCR. RNA was extracted with TRIzol (Invitrogen, Carlsbad, CA) and followed by cDNA synthesis with Revertaid Reverse Transcriptase (Fermentas, Pittsburgh, PA). Quantitative PCR was performed using the TaqMan Gene Expression Assays. Predesigned primers and probes for Aicda and Gapdh were ordered from Applied Biosystems (Carlsbad, CA), and data were normalized to Gapdh mRNA expression. To detect germ-line $\alpha$ transcripts, the primers I $\alpha$ F (5'-CCAGGCATGGTTG AGATAGAGATAG- $3^{\prime}$ ) and C $\alpha$ R (5'-GAGCTGGTGGGAGTGTCA GTG-3') were used. ${ }^{26}$ CT were detected by a nested PCR using the outer primers I $\mu 4\left(5^{\prime}\right.$-ACCCTGGATGACTTCAGTGT- $\left.3^{\prime}\right)$ and I $\alpha u p 4$ $\left(5^{\prime}\right.$-CATCTGGACTCCTCTGCTCA- $\left.3^{\prime}\right)$ followed by the inner primers I $\alpha \mathrm{F}$ ( $5^{\prime}$-CCAGGCATGGTTGAGATAGAGATAG- $\left.3^{\prime}\right)$ and C $\mu$ R (5'-AATGGTGCTGGGCAGGAAGT- $\left.3^{\prime}\right){ }^{26}$ Postswitch $\alpha$ transcripts were detected with the primers $\mathrm{I} \mu \mathrm{F}$ ( $5^{\prime}$-GAGCTGGTGGG AGTGTCAGTG- $\left.3^{\prime}\right)^{17}$ and C $\alpha$ R. Aliquots of PCR products were visualized by electrophoresis on $1.5 \%$ agarose gels.

Immunofluorescence. Deparaffinized and rehydrated Peyer's patch sections were incubated for an hour with biotinylated-GL-7 (eBioscience) and FITC-B220 (clone RA3-6B2, Biolegend), followed by incubation with AlexaFluor 594-streptavidin (Jackson ImmunoResearch Laboratories). Images were taken and analyzed with an Olympus BX51 imaging system (Center Valley, PA).

Statistical analysis. For comparisons between samples, the levels of significance were determined by Student's $t$-test in Prism 5.0 (Graphpad, La Jolla, CA). Where appropriate, mean \pm s.e.m. is represented on graphs.

\section{ACKNOWLEDGMENTS}

We thank Mats Bemark and Peter Bergqvist of the University of Gothenburg, Sweden for critical advice in the detection of IgA CSR, $\alpha$ germ-line transcripts, and $\alpha$ postswitch transcripts. This work was supported by NIH grants DK079918 and DK098370 and John Sealy Memorial Endowment Fund. A.T.C. is a recipient of the J.W. McLaughlin Postdoctoral Fellowship, UTMB.

\section{DISCLOSURE}

The authors declared no conflict of interest.

(c) 2015 Society for Mucosal Immunology

\section{REFERENCES}

1. Kuchroo, V.K., Ohashi, P.S., Sartor, R.B. \& Vinuesa, C.G. Dysregulation of immune homeostasis in autoimmune diseases. Nat. Med. 18, 42-47 (2012).

2. Feng, T. \& Elson, C.O. Adaptive immunity in the host-microbiota dialog. Mucosal Immunol. 4, 15-21 (2011).

3. Lycke, N.Y. \& Bemark, M. The role of Peyer's patches in synchronizing gut IgA responses. Front. Immunol. 3, 329 (2012).

4. Cerutti, A. \& Rescigno, M. The biology of intestinal immunoglobulin A responses. Immunity 28, 740-750 (2008).

5. Benckert, J. et al. The majority of intestinal $\lg A+$ and $\lg G+$ plasmablasts in the human gut are antigen-specific. J. Clin. Invest. 121, 1946-1955 (2011).

6. Talham, G.L., Jiang, H.Q., Bos, N.A. \& Cebra, J.J. Segmented filamentous bacteria are potent stimuli of a physiologically normal state of the murine gut mucosal immune system. Infect. Immun. 67, 1992-2000 (1999).

7. Suzuki, K. et al. Aberrant expansion of segmented filamentous bacteria in IgA-deficient gut. Proc. Natl. Acad. Sci. USA 101, 1981-1986 (2004).

8. Lecuyer, E. et al. Segmented filamentous bacterium uses secondary and tertiary lymphoid tissues to induce gut IgA and specific T helper 17 cell responses. Immunity 40, 608-620 (2014).

9. Mitsdoerffer, M. et al. Proinflammatory T helper type 17 cells are effective B-cell helpers. Proc. Natl. Acad. Sci. USA 107, 14292-14297 (2010).

10. Crispin, J.C. \& Tsokos, G.C. Interleukin-17-producing Tcells in lupus. Curr. Opin. Rheumatol. 22, 499-503 (2010).

11. Crispin, J.C., Kyttaris, V.C., Terhorst, C. \& Tsokos, G.C. T cells as therapeutic targets in SLE. Nat. Rev. Rheumatol. 6, 317-325 (2010).

12. Bubier, J.A. et al. A critical role for $I L-21$ receptor signaling in the pathogenesis of systemic lupus erythematosus in BXSB-Yaa mice. Proc. Natl. Acad. Sci. USA 106, 1518-1523 (2009).

13. Dolff, S. et al. Increase in IL-21 producing T-cells in patients with systemic lupus erythematosus. Arthritis Res. Ther. 13, R157 (2011).

14. Cao, A.T., Yao, S., Gong, B., Elson, C.O. \& Cong, Y. Th17 cells upregulate polymeric Ig receptor and intestinal $\lg A$ and contribute to intestinal homeostasis. J. Immunol. 189, 4666-4673 (2012).

15. Hirota, K. et al. Plasticity of Th17 cells in Peyer's patches is responsible for the induction of T cell-dependent IgA responses. Nat. Immunol. 14, 372379 (2013) 
16. Avery, D.T., Bryant, V.L., Ma, C.S., de Waal Malefyt, R. \& Tangye, S.G. IL-21-induced isotype switching to IgG and IgA by human naive $B$ cells is differentially regulated by IL-4. J. Immunol. 181, 1767-1779 (2008).

17. Seo, G.Y., Youn, J. \& Kim, P.H. IL-21 ensures TGF-beta 1-induced IgA isotype expression in mouse Peyer's patches. J. Leukoc. Biol. 85, 744-750 (2009).

18. Cong, Y., Feng, T., Fujihashi, K., Schoeb, T.R. \& Elson, C.O. A dominant, coordinated $\mathrm{T}$ regulatory cell-IgA response to the intestinal microbiota. Proc. Natl. Acad. Sci. USA 106, 19256-19261 (2009).

19. Nurieva, R.I. et al. Generation of T follicular helper cells is mediated by interleukin-21 but independent of $\mathrm{T}$ helper 1,2 , or 17 cell lineages. Immunity 29, 138-149 (2008).

20. Kolls, J.K. \& Khader, S.A. The role of Th17 cytokines in primary mucosal immunity. Cytokine Growth Factor Rev. 21, 443-448 (2010).

21. Lecart, S. et al. IL-22, in contrast to IL-10, does not induce Ig production, due to absence of a functional IL-22 receptor on activated human B cells. Int. Immunol. 14, 1351-1356 (2002).

22. Gelebart, P., Zak, Z., Dien-Bard, J., Anand, M. \& Lai, R. Interleukin 22 signaling promotes cell growth in mantle cell lymphoma. Transl. Oncol. 4, 9-19 (2011).

23. Watanabe, K. et al. Requirement for Runx proteins in IgA class switching acting downstream of TGF-beta 1 and retinoic acid signaling. J. Immunol. 184, 2785-2792 (2010).

24. Mora, J.R. et al. Generation of gut-homing IgA-secreting B cells by intestinal dendritic cells. Science 314, 1157-1160 (2006).

25. Kinoshita, K., Harigai, M., Fagarasan, S., Muramatsu, M. \& Honjo, T. A hallmark of active class switch recombination: transcripts directed by promoters on looped-out circular DNAs. Proc. Natl. Acad. Sci. USA 98, 12620-12623 (2001).

26. Bergqvist, P., Gardby, E., Stensson, A., Bemark, M. \& Lycke, N.Y. Gut IgA class switch recombination in the absence of CD40 does not occur in the lamina propria and is independent of germinal centers. J. Immunol. 177, 7772-7783 (2006).

27. Dullaers, M. et al. A T cell-dependent mechanism for the induction of human mucosal homing immunoglobulin A-secreting plasmablasts. Immunity 30, 120-129 (2009).

28. Feng, T., Cong, Y., Qin, H., Benveniste, E.N. \& Elson, C.O. Generation of mucosal dendritic cells from bone marrow reveals a critical role of retinoic acid. J. Immunol. 185, 5915-5925 (2010).
29. Feng, T., Qin, H., Wang, L., Benveniste, E.N., Elson, C.O. \& Cong, Y. Th17 cells induce colitis and promote Th1 cell responses through IL-17 induction of innate IL-12 and IL-23 production. J. Immunol. 186, 6313-6318 (2011).

30. Chames, P., Van Regenmortel, M., Weiss, E. \& Baty, D. Therapeutic antibodies: successes, limitations and hopes for the future. Br. J. Pharmacol. 157, 220-233 (2009).

31. Hammerschmidt, S.I. et al. Retinoic acid induces homing of protective T and $\mathrm{B}$ cells to the gut after subcutaneous immunization in mice. J. Clin. Invest. 121, 3051-3061 (2011).

32. Ouyang, W., Kolls, J.K. \& Zheng, Y. The biological functions of T helper 17 cell effector cytokines in inflammation. Immunity 28, 454-467 (2008).

33. Kuchen, S. et al. Essential role of IL-21 in B cell activation, expansion, and plasma cell generation during CD4 $+\mathrm{T}$ cell-B cell collaboration. J. Immunol. 179, 5886-5896 (2007).

34. Zotos, D. et al. IL-21 regulates germinal center $B$ cell differentiation and proliferation through a B cell-intrinsic mechanism. J. Exp. Med. 207, 365378 (2010).

35. Ertesvag, A., Naderi, S. \& Blomhoff, H.K. Regulation of B cell proliferation and differentiation by retinoic acid. Semin. Immunol. 21, 36-41 (2009).

36. Kalampokis, I., Yoshizaki, A. \& Tedder, T.F. IL-10-producing regulatory B cells (B10 cells) in autoimmune disease. Arthritis Res. Ther. 15, S1 (2013).

37. Hodge, L.S. et al. IL-21 in the bone marrow microenvironment contributes to IgM secretion and proliferation of malignant cells in Waldenstrom macroglobulinemia. Blood 120, 3774-3782 (2012).

38. Rodriguez-Bayona, B., Ramos-Amaya, A., Bernal, J., Campos-Caro, A. \& Brieva, J.A. Cutting edge: IL-21 derived from human follicular helper T cells acts as a survival factor for secondary lymphoid organ, but not for bone marrow, plasma cells. J. Immunol. 188, 1578-1581 (2012).

39. Fagarasan, S., Kinoshita, K., Muramatsu, M., Ikuta, K. \& Honjo, T. In situ class switching and differentiation to IgA-producing cells in the gut lamina propria. Nature 413, 639-643 (2001).

40. Bergqvist, P., Stensson, A., Lycke, N.Y. \& Bemark, M. T cell-independent IgA class switch recombination is restricted to the GALTand occurs prior to manifest germinal center formation. J. Immunol. 184, 3545-3553 (2010).

41. Nurieva, R.I. et al. Bcl6 mediates the development of T follicular helper cells. Science 325, 1001-1005 (2009).

42. Cong, $Y$. et al. CD4 + T cells reactive to enteric bacterial antigens in spontaneously colitic $\mathrm{C} 3 \mathrm{H} / \mathrm{HeJ}$ Bir mice: increased $\mathrm{T}$ helper cell type 1 response and ability to transfer disease. J. Exp. Med. 187, 855-864 (1998). 